\title{
Analysis of Wireless Connectivity Applications at Airport Surface
}

\author{
Shahid Ayub \\ Center for Autonomous and Cyber \\ Physical Systems \\ SATM, Cranfield University \\ MK43 0AL, UK \\ shahid.ayub@cranfield.ac.uk
}

\author{
Ivan Petrunin \\ Center for Autonomous and Cyber \\ Physical Systems \\ SATM, Cranfield University \\ MK43 0AL, UK \\ shahid.ayub@cranfield.ac.uk \\ Zhengjia Xu \\ Center for Autonomous and Cyber \\ Physical Systems \\ SATM, Cranfield University \\ MK43 0AL, UK \\ Zhengjia.Xu@cranfield.ac.uk
}

\author{
Antonios Tsourdos \\ Center for Autonomous and Cyber \\ Physical Systems \\ SATM, Cranfield University \\ MK43 OAL, UK \\ a.tsourdos@cranfield.ac.uk
}

\begin{abstract}
The main objective of the current work is to carry out the research to explore the potential wireless communication technologies that can be used during a flight operation at the airport surface for current and potential data applications in future. An important part of this work is the analysis of these services and applications from the perspective of understanding the stakeholders and communication means involved. Different communication services including both critical and non-critical ones are analyzed for aircrafts, airlines, and airport connectivity covering flight stages from landing at the airport to taking off from the airport. We are also proposing the ways of more effective use of communication means including the proposed measures for throughput improvement in order to better meet the needs of the airport stakeholders.
\end{abstract}

Keywords-Airport connectivity, Datalink systems, In- Flight Entertainment, Situational awareness of airline operations, Network performance, Load balancing

\section{INTRODUCTION}

The rapid advancement in wireless sensor technologies and cooperative network protocols development have made it possible to equip future aircraft $(\mathrm{A} / \mathrm{C})$ with multiple wireless sensors systems. These sensors will generate a huge amount of data concerning operations, maintenance, and surveillance that need to be transferred wirelessly to airport ground control center through high-speed wireless data links. The significant efforts have been made to enhance the performance of air traffic management (ATM), connectivity at airport surface and inflight entertainment (IFE) by introducing new operational concepts using automation systems. These new operational concepts include improved surface operations, low visibility operations, collaborative decisions for ATM, performancebased navigation, improved weather and navigation information, etc.

Airlines are also determined to deploy wireless applications in future to transfer the traditional paper-based services like airline administration operations and passengers' detail to the aircraft crew. Different airlines have different route structures, airport facilities, IT organizations and fleet preparation; therefore, ground-based wireless connections and their operations will vary greatly.
Stakeholders of airport connectivity (shown in Figure 1), such as ATM, airlines, air navigation service providers (ANSP), ground services, security, UK border agency, police, fire service, etc., operating at or around airports increasingly recognize the need for transparent and collaborative processes that require sharing of information through a secure, reliable and high-speed communication channel.

Airport collaborative decision-making (ACDM) concept starts with information sharing and expands on making capacity related decisions in a collaborative manner on the day of operations. It aims at improving the overall efficiency of airport operations by optimizing the use of resources, and improving the predictability of events.

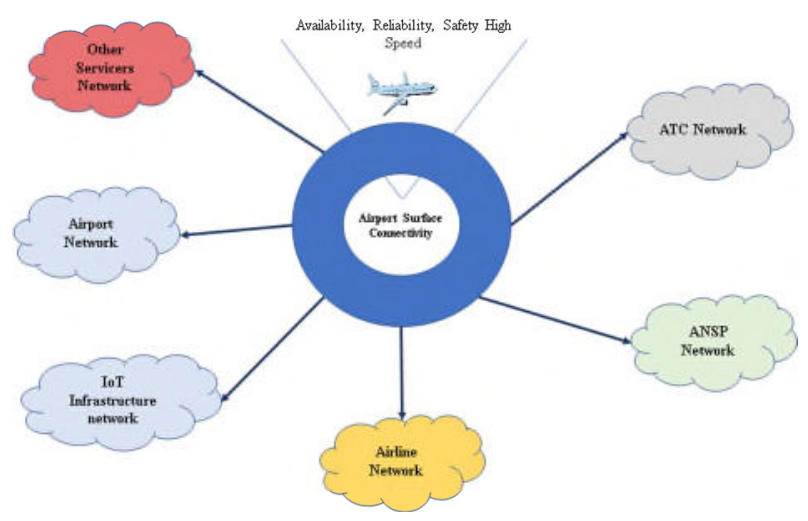

Fig. 1. Airport Connectivity

Currently, there is no standardized or globally agreed single data communication system deployed for simultaneous airline and airport operations. Various state of the art commercial systems: cellular / Wi-Fi solutions, Gatelink, etc. are in operation at various airports [1]. These are not used for air traffic control (ATC) communication due to the issues of reliability, availability, and security. For ATC and ATM communications, very high frequency (VHF), aeronautical Communication and Reporting System (ACARS) and Satellite communication (SATCOM) systems are available at airports at present. The VHF has limited spectrum and is already fully 
occupied having traffic congestions issues and does not have capability to support the rapidly growing air traffic and future high-speed data applications. SATCOM is costly solution and does not provide good connectivity at airport surface due to interference and buildings.

In [2], different network scenarios were simulated for Aeronautical Mobile Airport Communications System (AeroMACS) solution for complete airport area. It was concluded that ATC applications do not significantly contribute to data traffic compared to AOC Applications at airport surface. The networks based on Wi-Fi Gatelink, SATCOM, and cellular technologies have been considered and communication profiles have been recommended to transmit data over these IP networks in [3]. It was observed from the results achieved for cellular technologies and Wi-Fi systems [3] that Wi-Fi was superior in all scenarios. Average throughput performance values achieved were between 4.5 Mbps and 13.6 Mbps for download, and between 3.2 and 20.525 Mbps for upload in the airport gate zone or remote hanger.

The general overview of the present use of communication technologies at the airports can be obtained from the results of recent survey of EUROCONTROL, presented in [4]. EUROCONTROL Communications, Navigation, \& Surveillance (CNS) and Aircraft Operator (AO) teams successfully surveyed a number of stakeholders about current communication means used by the survey participants. 130 participants, from ANSPs, airport operators and airspace users participated in the survey. The information was obtained from the answers on the question that which communication services are currently provided at airport surface and which technology is used for providing these services. The main findings of the survey include: 1) VHF and ACARS remain the most widely used technologies for communication at airport using various voice or data services. 2) The main drawbacks reported for VHF and ACARS are throughput, cost, coverage, and interference. 3) Within the next 10 years, ANSPs plan to implement AeroMACS and VHF as communications platforms, while airports and airspace users plan to go with a diversified implementation, consisting of AeroMACS, Wi-Fi, and/or commercial networks. Therefore, it is essential to explore the potential wireless communication technologies for providing various data and voice services operated by different stakeholders during a flight operation at the airport surface in future.

Rest of the paper is organized as follows: In section II, the components of Airport connectivity have been outlined including stakeholders and data services involved at airport surface. Section III summarizes the potential wireless communication technologies available for airport surface and provides a comparison of wireless communication technologies (AeroMACS, LTE-A, Wi-Fi, mmWave).

Section IV provides an overview of the high data demanding applications scenario for communication between $\mathrm{A} / \mathrm{C}$ and stakeholders along with their requirement analysis and bearer assignment to each scenario with outlined recommendations. In Section $\mathrm{V}$, techniques and methods have been discussed to increase the network performance under specified data applications at airport surface. Finally, conclusions are drawn in Section VI.

\section{AIRPORT CONNECTIVITY}

Aircraft turnaround time is the most important factor for an airline to reduce the costs. There are multiple tasks that contribute to aircraft turnaround time at airport surface, which can include air traffic control operations, maintenance tasks, pre/post flight operations, fuel supply, catering, cleaning, deicing, baggage handling, passenger stairs, pushback vehicles etc. All of the above stakeholders must coordinate with each other in order to achieve peak efficiency. With a common platform for data connectivity for all these stakeholders, it is possible to maximize performance by making collaborative and prompt decisions and actions. In the following section, different components of airport connectivity have been described.

\section{A. Airport Types}

The type of the airport is linked to number and size of the airlines it hosts and respectively to the number of services provided for aviation stakeholders and communication technologies used for that.

The commonly used UK classification of airports recognizes four types of airports [4].

1. Gateway International Airports, which are supplying a wide range and frequency of international services, including intercontinental services and a full range of domestic services

2. Regional Airports, catering to the main air traffic demand of individual regions. They are concerned with the provision of a network of short-haul international services and a range of charter services and domestic services, including the links to gateway airports.

3. Local Airports, which are providing third level services (e.g. scheduled passenger services operated by aircrafts with fewer than 25 seats), catering privately for local needs, concentrating on general aviation with some feeder services and some charter flights.

4. General Aviation Airports are concerned primarily with the provision of general aviation facilities.

In addition to type of the airports, there is also a need to consider interoperability issues while installing network infrastructure at different geographical airports.

\section{B. Flight Operation Zones}

The communication with aircraft comprises of several services, which are triggered while the aircraft moves from one zone to other zone on the airport surface. Figure 2 shows different zones of aircraft flight operations. These zones include Gate, Taxi, Tower, Take-off, Cruise and Landing zones [2]. Gate zone denotes the location where an aircraft stays at the gate before departure/after arrival, Taxi zone include the area from push back and where taxiing to the runway is completed and Tower zone is the zone after control is handed over from taxi 
zone to tower for take-off or from tower to taxi zone during landing.

This research work is considering the airport connectivity scenarios only at the airport surface that include three zones of aircraft flight operations, which are Gate, Taxi and Tower.

\section{Stakeholders Involved in Flight Operations}

Airport is an essential part of the air transport system because it is the physical site where a modal transfer is made from the air mode to the land mode or vice versa. Therefore, it is the point of interaction of the major stakeholders of the air transport system [4] which include:

\section{$>$ Air Traffic Management (ATM) \\ $>$ Airline Companies \\ $>$ Airport Authority}

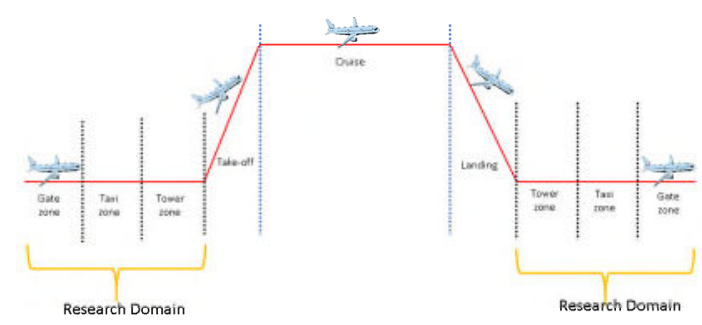

Fig. 2. Airport Zones

The objective of ATM is to handle A/C movements safely, increase airport capacity and reduce environmental impact. Airline's and airport's objectives include improving operations (fuel, catering, baggage handling, etc.), passengers' satisfaction and additional revenue by meeting minimum regulatory requirements.

Above stakeholders are participating directly or indirectly in data communication services at airport surface. However, the number of actors operating at different airports may vary by size of airlines and airports.

A high-level overview of actors involved in airport operations is shown in Figure 3. It provides us the information on the generic aspect of airport operations. It is also expected that list of stakeholders and links between them will be significantly affected by the type of the airport, i.e. for type 4 airports (General Aviation) it is reasonable to accept significant reduction in number of stakeholders involved into communication activities at the airport surface as well as complexity of their interaction.

\section{Data Services at Airport Surface}

This section presents existing and potential data services and applications [5], [6] related to airport surface operations which needs to be supported by wireless solutions to be deployed at airport in future.

\section{1) Air Traffic Management Services}

As the air traffic congestion grows, there is a need to manage air traffic, improve energy efficiency and decrease the cost of air traffic control. Air traffic controller shares the data and provide advisory services to airlines both on ground and to aircraft. Possible current and future applications in ATM domain might be:

- Air/ground voice and data communications - Messages that are currently conveyed over the VHF voice and aircraft communications addressing and reporting system (ACARS) (e.g., pre-departure clearance).

- Advisory services- NOTAMs, weather, traffic, events etc.

- Controller pilot data link communications (CPDLC) messages (e.g., Future 4-dimensional trajectory).

- Safety-critical applications (e.g., activate runway lighting systems from cockpit (D-LIGHTING)).

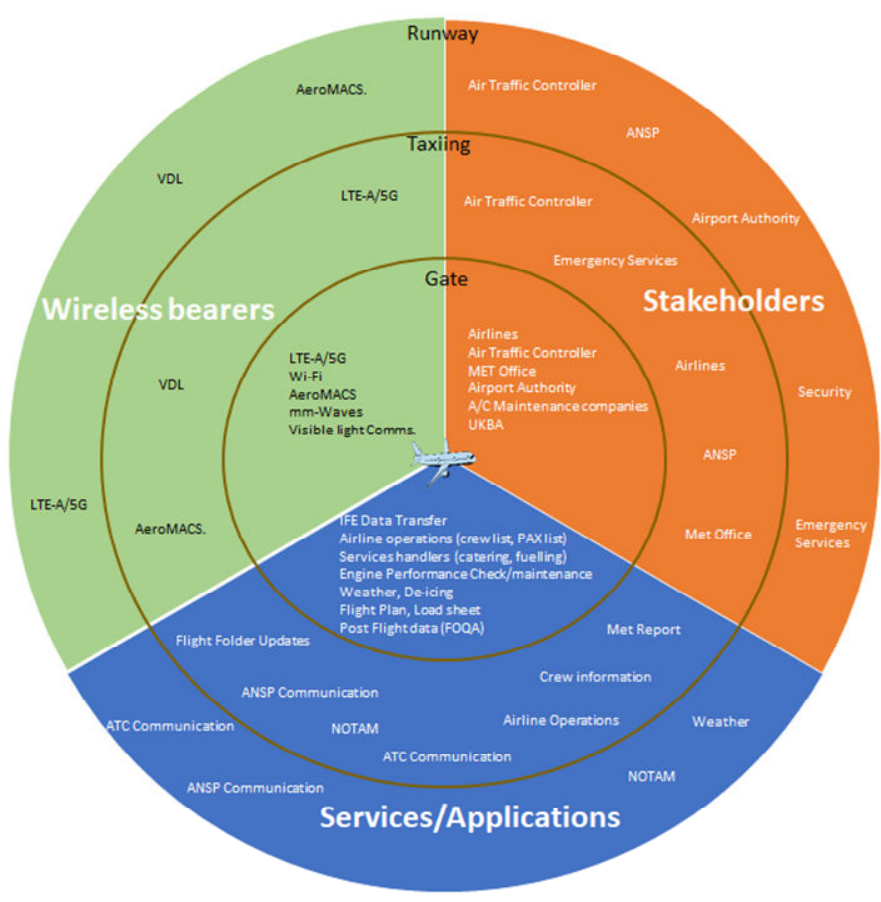

Fig. 3. Airport Connectivity Structure

- Support for airport surface surveillance and navigation capability- Navigation (e.g., instrument landing system data and visibility data for runway visual range), Surveillance (e.g., airport surface movement detectionASDE, and airport surveillance radar- ASR).

- Airport surface information guidance for situational awareness (D-SIG), ground connectivity to flexible terminal sensor network (FSTN) including weather stations, runway visual range sensors and low-level wind shear alert system sensors.

- Remote maintenance and monitoring (RMM).

- Controller pilot data link communications (CPDLC) - D Taxi. 


\section{2) Airline Services}

Airline data services have the [7],[8] potential to become significant drivers of future communication technology design because of several high-volume data synchronization services. These services include:

- The AIS synchronization services (e.g., uploading flight plans to the FMS, aerodrome charts to electronic flight bag).

- Upload of time sensitive In-flight entertainment data, flight operations quality assurances (FOQA) data, engine performance data, and cabin logbook entries that enable rapid response to aircraft problems and tuning of flight performance parameters for maximum flight efficiency.

- Weather Information graphical forecast meteorological information maps, weather advisory, turbulence guidance maps (updating terrain and global positioning satellite navigational databases)

- Data delivery to the cockpit (e.g. data link aeronautical update services (DAUS), and airport/runway configuration information).

- Ground operations and services (e.g., coordination of refuelling and de-icing operations).

- Communication with ground staff.

- Tracking of ground vehicles and other mobile assets.

- $\quad$ Luggage management.

- $\quad$ Aircraft operations (e.g., updates to flight operations manuals and weight and balance information required for take-off).

- Remote control troubleshooting of aircraft.

- $\quad$ NOTAMs (both textual \& graphical).

- Moving map (video) display of airport with runway incursion alert.

\section{3) Airport Authority Services}

Airport authority plays a pivotal role in airport connectivity as it provides an efficient, reliable and secure broadband connectivity across the entire airport. It has responsibility of security and safety of the environment.

Service operated by Airport authority include [9], [10]:

- Communication with pilots and crew to coordinate flight operations, ground operations, and emergencies.

- Communication with ground staff and airport vehicles.

- The airport or port authority operations are dominated by video applications required for safety services (e.g., fixed surveillance cameras and in-vehicle and portable mobile cameras for live video feeds and voice communications with central control during snow removal, de-icing, security, fire, and rescue operations).
- Reporting the status of airport runway and taxiway lights and monitoring and maintenance of navigational aids and time critical airfield signage these services are currently provided through VHF voice and data links, land mobile radio services, and commercial local area wireless networks.

- Wireless backhaul connection for airport surface detection equipment (ASDE-X). ASDE-X data is combined with surface movement radar data and aircraft transponder information to display detailed information about aircrafts and vehicles position.

- Data uploads/downloads with fixed connected terminals.

- Ground safety and security, including radar, perimeter surveillance, runway incursion prevention, airfield lighting, and detection of intruders, foreign object damage (FOD) and wildlife.

- ATC surveillance and clearance.

To increase the overall efficiency and reduce turnaround time at airport, a centralized communication system is needed that coordinate different services offered by various stakeholders. This will help in taking prompt decisions and actions hence reducing un-necessary delays produced due to lack of communication among these services.

\section{WIRELESS TECHNOLOGIES FOR AIRPORT CONNECTIVITY}

This section discusses wireless solutions for airport connectivity. Currently, wireless technologies used in cruise zone include HF, VHF, SATCOM, while on board internet facility is provided using Swift BroadBand technology (SBB). At airport surface, various state of the art commercial systems (cellular / Wi-Fi solutions, custom/proprietary systems, etc.) are in operation. These are not used for ATC communication due to the issues with reliability, availability, and security.

For air traffic control \& management communications, VHF, ACARS and SATCOM systems are available at most of the airports. EUROCONTROL, SESAR, and FAA have jointly agreed on a single solution [7],[11],[12],[13],[14] and recommended AeroMACS as the only globally standardized aviation technology designed to support the safety and regularity of flight, ATC, AOC, and Airport communications simultaneously in future [2]. However, for certain high data traffic applications, like IFE update, post flight data offload, other wireless solutions can also be considered to compliment AeroMACS and maximize efficiency.

Airlines also needs to consider the following operational requirements when choosing to implement wireless communication systems for airport surface connectivity [15]:

- High bandwidth data connection is required that can enable transfer of larger data sets during an aircraft's gate operations, taxing or while at a maintenance facility.

- Upload of time sensitive IFE data, Flight Operations Quality Assurances (FOQA) data offload, engine 
performance data, and cabin logbook entries that enable rapid response to aircraft problems and tuning of flight performance parameters for maximum flight efficiency.

- Timely download of flight specific data sets, e.g., daily news, and sports programs, movies, games that enhance the passenger experience.

\section{A. Wireless bearers}

In the following section a comparison of current and future proposed wireless technologies for voice and data communication networks for airport surface connectivity has been provided. Figure 4 shows the different wireless technologies for airport connectivity that includes, Wi-Fi, mmWave, optical and cellular based solutions

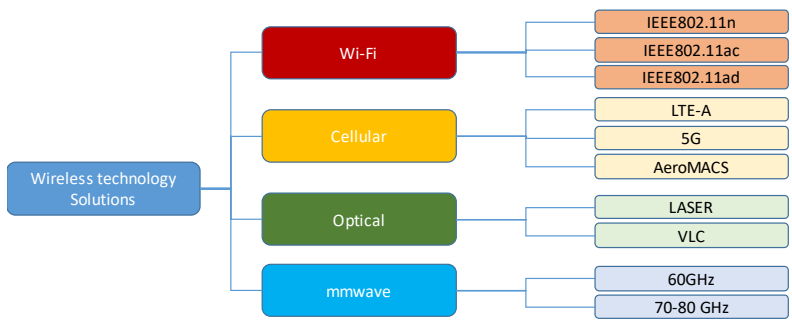

Fig. 4. Wireless Communication Technologies at Airport Surface

\section{1) Wi-Fi Solutions}

Wi-Fi standards have evolved over the years to provide a greater bandwidth to use different frequency bands that offer less potential for interference from other devices [15],[3]. The following sections provide a functional description of the different IEEE standards Wi-Fi technologies.

IEEE802.11n is an improvement over the IEEE802.11 standards. It utilizes Multiple Input and Multiple Output (MIMO) technology in the $2.4 \mathrm{GHz}$ and $5 \mathrm{GHz}$ band. It uses spatial division multiplexing (SDM) and large channel bandwidth $(20$ or $40 \mathrm{MHz}$ ) to increase throughput. The maximum standardized antenna setup for IEEE802.11n is 4X4:4- meaning four antennas for transmission, four for receiving and allowing a maximum of four spatial streams [15],[9]. To improve user level throughput, IEEE802.11n introduces frame aggregation in order to reduce protocol overhead. IEEE802.11n provides data rate between $40 \mathrm{Mbps}$ to $600 \mathrm{Mbps}$ using OFDM modulation. The maximum achievable net data rate depends on the configuration of the sender and receiver (e.g., number of antennas, utilization of $40 \mathrm{MHz}$ channels, etc.). It is backward compatible to IEEE 802.11a, IEEE $802.11 \mathrm{~b}$, and IEEE802.11g. Since $5 \mathrm{GHz}$ band for IEEE $802.11 \mathrm{n}$ is not fully authorized in all regulatory domains in different geographical areas so it requires a careful consideration of using available channels in ground-based applications.

IEEE802.11ac specifies up to 8 streams (8X8:8) and uses a channel width of 80 to $160 \mathrm{MHz}$. In order to reduce interference with other stations or network participants, the IEEE802.11ac incorporates standardized beamforming. IEEE802.11ac provides a throughput of 1 Gbps using a high-density modulation schemes (256QAM). The IEEE802.11 ac works in 5 $\mathrm{GHz}$ band and provides coexisting mechanism for IEEE802.11n and IEEE802.11ac. Caution is advised when using IEEE802.11ac channels, so that implemented channels are available in different regulatory domains when aircraft moves from one geographical area to other area.

IEEE802.11 ad was proposed by the wireless gigabit alliance (Wi-Gig). It specifies a maximum throughput of 7 Gbps. In order to achieve this high throughput, IEEE 802.11ad operates in $2.4 \mathrm{GHz}, 5 \mathrm{GHz}$ and $60 \mathrm{GHz}$ bands. For the maximum throughput, the $60 \mathrm{GHz}$ band is used. It cannot penetrate through walls and requires line of sight communications. To overcome this situation, IEEE802.ad switches to 2.4 or $5 \mathrm{GHz}$ bands whenever sender and receiver have no direct line of sight between them. This, however, reduces the maximum achievable throughput. Similar to IEEE 802.11ac, it utilizes beamforming in order to keep interference with other stations minimum. IEEE802.11 ad is backward compatible to IEEE802.11n.

Wi-Fi channels typical overlap in a given frequency band and thus operating channels should be chosen carefully to minimize interference with other transmitters nearby.

Airlines should consider the following technical considerations:

- Airlines must follow individual country regulations for the channels offered in each frequency band.

- The $2.4 \mathrm{GHz}$ frequency band is usually very crowded and it is recommended to operate on the $5 \mathrm{GHz}$ and 60 $\mathrm{GHz}$ bands if possible.

- Continuously monitor the channels which are occupied or free using some wireless measurement tool. A channel is selected for communication which is still free or which has a very weak signal from other base stations.

2) Cellular Technologies Solutions

Cellular technology is one of the potential candidates for future airport connectivity. The following section gives a brief overview of current cellular technologies. 3G cellular technology supports maximum throughput data rates of $42 \mathrm{Mbps}$ when high speed access (HSPA) is implemented in the network but users in deployed network can expect a transfer rate of up to $384 \mathrm{kbps}$ for the original UMTS release, and 7.2 Mbps for high speed downlink packet access (HSDPA) handsets in the downlink connection. Currently, downlink transfer speeds for UMTS are up to $21 \mathrm{Mbps}$ [4]. 4G (LTE, LTE-Advanced) specifications provides downlink peak rates of $100 \mathrm{Mbps}$, uplink peak rates of $50 \mathrm{Mbps}$. It operates in $700 \mathrm{MHz}, 2100 \mathrm{MHz}$, and $2300 \mathrm{MHz}$ frequency bands. Mobile operators are establishing international mobile roaming agreements to provide roaming services to subscribers. Operators must consider that countries have allocated different frequency bands like 900/1800 and $850 / 1900 \mathrm{MHz}$ bands. Devices can only work in a country with a different frequency allocation if they can support one or both of that country's frequencies [9]. In future 5G can replace LTEA technology. 


\section{3) AeroMACS}

AeroMACS is a broadband [16] wireless communication system that can support the secure and reliable transmission of flight data for both fixed and mobile applications at the airport surface. It is based on the WIMAX IEEE 802.16e standard and operate in the spectrum band from $5091 \mathrm{MHz}$ to $5150 \mathrm{MHz}$. AeroMACS has the capability to provide high throughput for airport surface communications resulting in a reduction of congestion of VHF spectrum at airports and delays consequently [12]. Its coverage is up to $5 \mathrm{~km}$ depending upon the propagation scenario, fixed or mobile services [1]. It can support mobility up to $57.5 \mathrm{mph}$ [17]. AeroMACS provides an efficient use of network and spectrum resources by enabling Quality of Services (QoS) features like prioritized traffic flow, coexistence of multiple applications (voice, data and video), etc.

\section{4) mmWave Solutions}

mmWave technology in V-Band $(60 \mathrm{GHz})$ and E-Band (70-80 $\mathrm{GHz}$ ) is gaining more popularity these days due to large channel bandwidth (up to $2 \mathrm{GHz}$ ) and high data rates of $10 \mathrm{GHz}$. It operates in both licenced $(60 \mathrm{GHz})$ and unlicensed bands $(70-$ $80 \mathrm{GHz}$ ). Its range varies from $10 \mathrm{~m}$ to $2 \mathrm{~km}$. mmWave uses beamforming techniques to provide LOS communication between end devices. Table I provides a comparison of potential candidates technologies to be used at airport surface. Visible Light Communication (VLC) can be considered as a future technology for high-speed data transfer applications like IFE and FOQA, however, currently VLC products complaint for aircraft communication are not available.

TABLE I. WIRELESS TECHNOLOGIES COMPARISON

\begin{tabular}{|c|c|c|c|c|}
\hline & AeroMACS & Wi-Fi & $L T E-A$ & mmWave \\
\hline $\begin{array}{l}\text { Frequency } \\
(\mathrm{GHz})\end{array}$ & $5.091-5.150$ & $2.4 / 5$ & $\begin{array}{l}0.8 / 0.9 / 1.8 / \\
1.9 / 2.3 / 2.6 \\
\end{array}$ & $60 / 70 / 80$ \\
\hline Spectrum & Licensed & Unlicensed & Licensed & $\begin{array}{c}\text { Licensed } \\
\text { /Unlicensed }\end{array}$ \\
\hline $\begin{array}{l}\text { Data rate } \\
(\mathrm{Mbps})\end{array}$ & upto10 & Multi-Gbps & Up to 100 & Multi-Gbps \\
\hline $\begin{array}{l}\text { Range } \\
(\mathrm{km})\end{array}$ & 3 & Up to $300 \mathrm{~m}$ & 30 & $\begin{array}{c}\text { Up to } \\
2 \mathrm{~km}(\mathrm{E}- \\
\text { band) }\end{array}$ \\
\hline $\begin{array}{l}\text { Channel } \\
\text { Bandwidth } \\
(\mathrm{MHz})\end{array}$ & 20 & $\begin{array}{c}20,40,80, \\
160\end{array}$ & $1.4-20$ & $1-2 \mathrm{GHz}$ \\
\hline $\begin{array}{l}\text { Latency } \\
(\mathrm{ms})\end{array}$ & $<10$ & $<100$ & $<5$ & $<5$ \\
\hline $\begin{array}{l}\text { Mobility } \\
(\mathrm{mph})\end{array}$ & 57.5 & walking & 280 & walking \\
\hline
\end{tabular}

\section{A. Inflight Entertainment Scenario}

IFE is one of the airline services that require large bandwidth and high data rates. The main objective of this service is to entertain the passengers and keep them updated with information, latest news and media contents. It includes transfer of media contents to aircraft, regular updates, secure data (credit card transactions) transfer, surveillance data, etc. Table II shows the different types of data applications delivered through IFE service.

In Figure 6, important stakeholders, required link parameters and wireless technologies suitable for IFE services have been identified. Airline is an important stakeholder in IFE services. IFE services are triggered as soon as aircraft comes at the gate zone. The average turnaround time for an aircraft is about 4550 minutes, and, to reduce the turnaround delays, IFE services 
needs to be downloaded to aircraft within this time period and therefore this transfer requires a multi-Gbps data links.

TABLE II. IN-FLIGHT ENTERTAINMENT SERVICES

\begin{tabular}{|c|c|c|}
\hline Entertain Passengers & Inform Passengers & Support Cabin Crew \\
\hline Airread & Concierge services & $\begin{array}{c}\text { Crew- to- Ground } \\
\text { Messaging }\end{array}$ \\
\hline $\begin{array}{l}\text { Audio/Video on } \\
\text { Demand }\end{array}$ & $\begin{array}{c}\text { Meal and Beverage } \\
\text { Menus }\end{array}$ & $\begin{array}{c}\text { Crew- to- Passenger } \\
\text { Messaging }\end{array}$ \\
\hline File viewer & Pay per Access & $\begin{array}{l}\text { Custom Script \& } \\
\text { Automation }\end{array}$ \\
\hline Games & Shopping & Parental Control \\
\hline $\begin{array}{l}\text { Personal Electronic } \\
\text { Device (PED) } \\
\text { Integration } \\
\text { Personalization }\end{array}$ & $\begin{array}{c}\text { Targeted } \\
\text { Advertisements }\end{array}$ & $\begin{array}{c}\text { Wireless Crew } \\
\text { Access }\end{array}$ \\
\hline $\begin{array}{l}\text { MyPath Journey } \\
\text { Interface } \\
\text { Web-based Apps }\end{array}$ & - & - \\
\hline
\end{tabular}

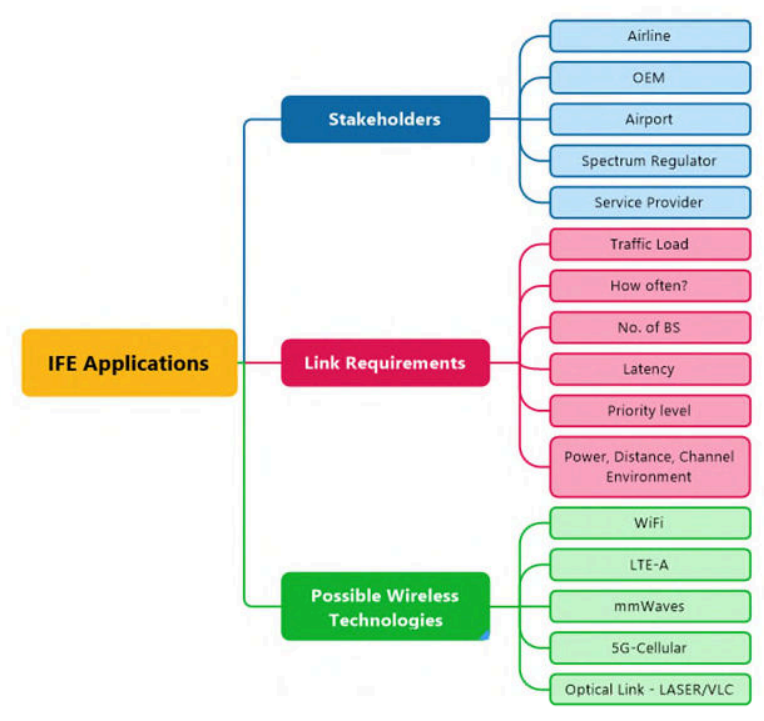

Fig. 6. Inflight Entertainment Scenario

An estimate of data volume of IFE applications and their frequency identified in [15] has been shown in the following Table III. The potential wireless bearers that may be used for these services include, Wi-Fi, mmWave, 5G/LTE-A and optical (Visible light communication or LASER) communication.

TABLE III. IFE DATA SIZE AND FREQUENCY

\begin{tabular}{llccc}
\multicolumn{1}{c}{ Type of Data } & Volume & Direction & Location & Schedule \\
\hline IFE Contents & $\sim 1 \mathrm{~GB}$ & Ground->A/C & Gate & Daily \\
Update & & & & \\
IFE Contents & $\sim 1 \mathrm{~TB}$ & Ground->A/C & Gate & Monthly \\
Load & & & & \\
\hline
\end{tabular}

The mmWave technology is the most suitable potential candidate for IFE services as shown in Table V. It can provide high data rates of up to $10 \mathrm{Gbps}$ using beam-forming techniques for LOS communication between end users.

\section{B. Situational Awareness of Airlines Operations}

Airline is an important stakeholder during flight operations. The main objectives of airline are to provide satisfactory services to passengers and reduce unnecessary turnaround delays occurred due to lack of coordination between different services offered directly or indirectly through third partners.

Aircraft crew and staff at ground control centre need to be updated about services carried out during each flight operation. The lack of coordination between different services creates delays; these delays can be avoided by providing a collaborative, integrated single communication system so that rapid decision can be made and actions can be taken.

Figure 7 shows the stakeholders involved in situational awareness applications scenario, link parameters required and suitable wireless technologies for situational awareness of airline operations.

Airline services can be divided into two main categories: 1) Airline Operation Control (AOC) and 2) Airline Administration Control (AAC). AOC include flight operations and ground operations. AAC include crew management and flight plan etc. Above two categories can be further divided into three phases of flight

- $\quad$ Pre-Flight Airline Services

- In-Flight Airline Services (Engine Start, Pushback, and Taxi)

- Post Flight Airline Services

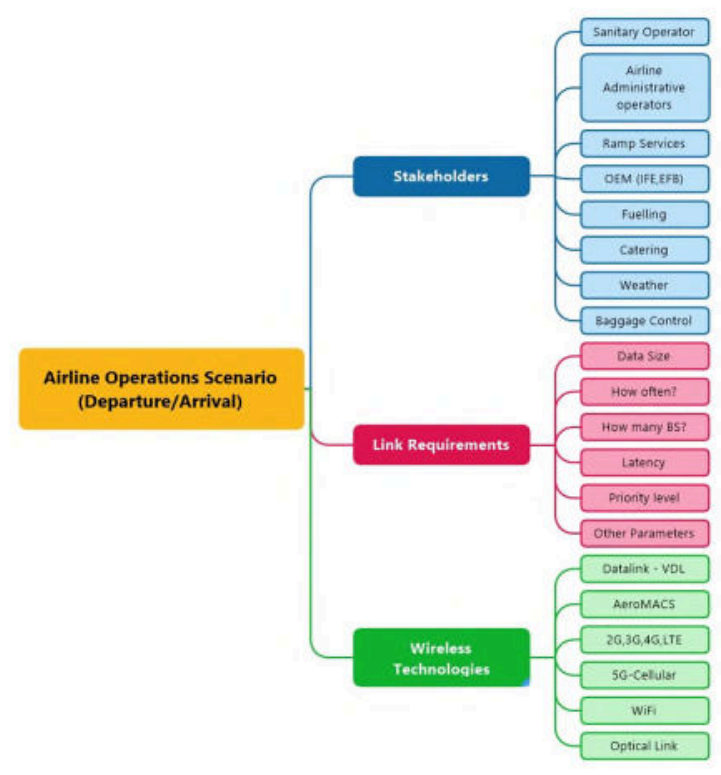

Fig. 7. Airline Operations Applications

Pre-flight operations are carried out while aircraft is at Gate zone and there is no mobility. Most of the high data traffic services are carried out at gate zone such as flight plan, preliminary and final load sheets transfer, Engine performance 
check data etc. Figure 8 shows the data services between aircraft and airline ground operation centre during pre-flight.

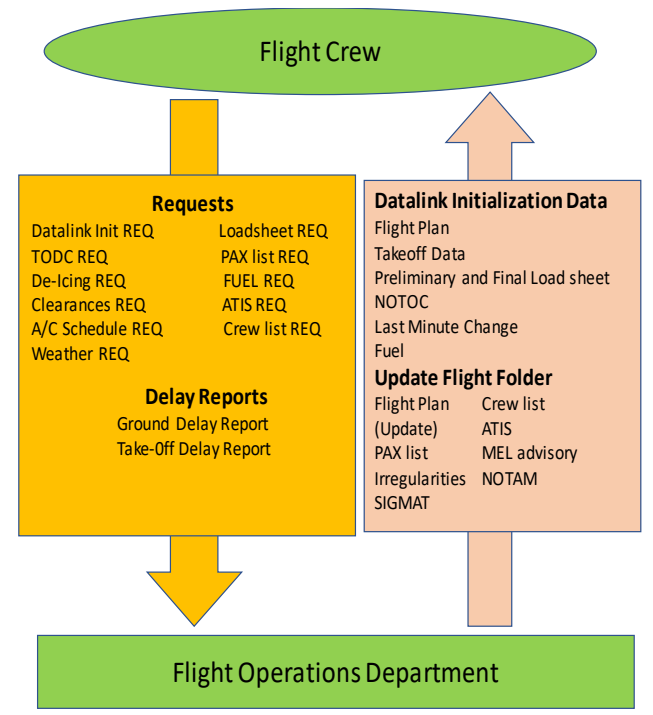

Fig. 8. Airline Datalink Applications - Pre-Flight



Fig. 9. Airline Datalink Applications - In-Flight (Pushback, Engine Start, and Taxi)

Figure 9 shows the data services during engine start, pushback, taxiing. The important application triggered in these zones include electronics flight folder and loadsheets updates. Figure 10 shows the post flight data services.

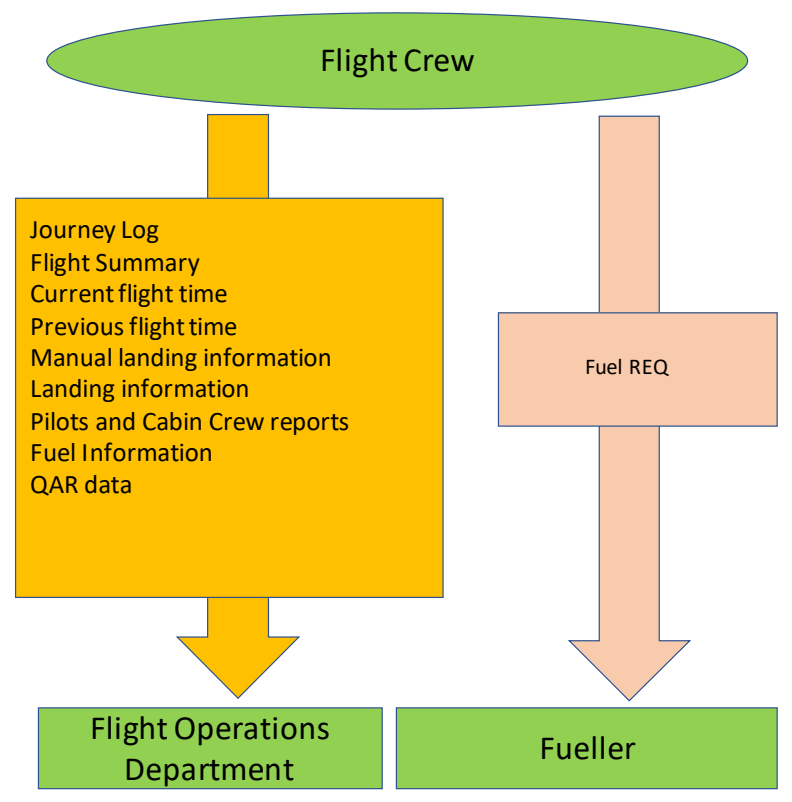

Fig. 10. Airline Datalink Applications - Post-Flight

After the analysis of these services for the airline operations scenario, we have identified the services with the highest data rate requirements and summarized them in Table IV.

TABLE IV. AIRLINE OPERATIONS

\begin{tabular}{lcccc}
$\begin{array}{l}\text { Applications/serv } \\
\text { ices }\end{array}$ & $\boldsymbol{R L}$ & $\boldsymbol{F L}$ & $\begin{array}{c}\boldsymbol{F L} \text { Data } \\
(\boldsymbol{M B})\end{array}$ & $\begin{array}{c}\boldsymbol{R} \text { L Data } \\
(\boldsymbol{M B})\end{array}$ \\
\hline FLTJOURNAL & 2 & 0 & 10 & 0 \\
FOQA & 1 & 0 & 100 & 0 \\
\hline EFF & 3 & 3 & 2 & 10 \\
EFFU & 1 & 2 & $10 \mathrm{~KB}$ & 1 \\
\hline UPLIB & 0 & 1 & 0 & 40 \\
E-CHARTS & 0 & 1 & 0 & 150 \\
\hline SWLOAD & 0 & 1 & 0 & 1
\end{tabular}

RL*- Reverse link (Aircraft to Ground), FL*- Forward Link (Ground to Aircraft)

It has been identified that for airline operations, data traffic is not as large as in case of IFE scenario, however airline operations involve mobility and require reliability, security and integrity during data transfer. We need a secure wireless network solution that can also support mobility and AeroMACS is suitable wireless bearer for airline operations as shown in Table V. 


\begin{tabular}{lcccc}
$\begin{array}{l}\text { Applications / } \\
\text { Services }\end{array}$ & Wi-Fi & 5G/LTE-A & AeroMACS & $\begin{array}{c}\text { mmWav } \\
\boldsymbol{e}\end{array}$ \\
\hline IFE Applications & 2 & 3 & 4 & 1 \\
$\begin{array}{l}\text { Airline } \\
\text { Applications }\end{array}$ & 3 & 2 & 1 & 4 \\
\hline
\end{tabular}

\section{NETWORK PERFormanCE OPTIMIZATION}

We are looking for a future communications solution for airports providing a converged, optimized multiservice network to streamline the operation conducted by airport operation managers and air traffic controllers and delivering the highest levels of operational efficiency. This section recommends following multiple solutions to increase channel utilization efficiency, network throughput and reducing network delays.

- Contention removal mechanisms

- Load balancing techniques

- Cell virtualization

- Seamless handover

In wireless systems, the channel utilization decreases significantly compared to Ethernet system with an increase in no of users as shown in Figure 11. This is because of nonaccessibility of available channels due to collisions [18]. As in case of Ethernet, there is physical channel and it is possible to detect if any collision occurs on the channel, however in case of wireless channel, it is not possible to detect the collisions due to its inherited half duplex nature, so a user has to wait until an acknowledgement is received or it retransmits the packet after waiting for a certain time period if acknowledgement is not received. In this case, user has to wait for longer period and channel utilization decreases drastically compared to Ethernet. This contention can be avoided by exploiting suitable contention windows for each user according to type of the data and priority level [19], [20].

Throughput can be increased by using channel-bonding options available in wireless technologies i.e., combining channels together to increase the channel bandwidth. For instance, in WiFi technologies, there is an option of $20,40,80$ and $160 \mathrm{MHz}$ channel combinations [21].

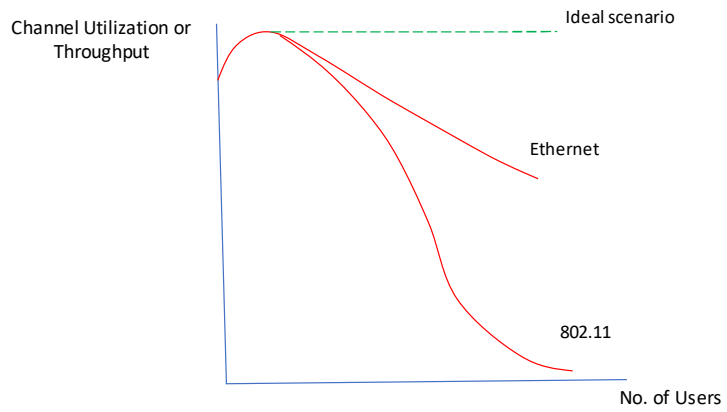

Fig. 11. Channel Utilization review of users

Spatial multiplexing and diversity can be utilized using MIMO technology to enhance the throughput of the system. Other methods of reducing contention delays are to reduce inter-frame spacing and increasing data length per frame using Media Access (MAC) aggregation and block acknowledgement mechanisms.

Network throughput can also be improved by sharing the load among multiple access points in a fair way. Each user is associated with access point according to stronger signal strength that can create situations where an access point may become more overloaded compared to neighbor access points. To avoid this situation, it is important to apply load-balancing techniques to associate the number of users to access points fairly. If an access point advertises its load and associated number of users to the neighboring access points, then neighboring access points will share the load equally that will help to reduce congestions in the network by utilizing resources efficiently and enhancing network performance [22]

Cell virtualization can increase the reliability and availability in the network by exploiting multi-tier layered architecture with redundant channels [23]. That will help to switch the channels in case of poor performance, seamless handover within access points and balance the traffic load among access points fairly.

\section{CONCLUSION}

This paper provides an overview to data services at the airport surface. It considers the existing and future data demands of these services offered by stakeholders involved directly or indirectly in provision of these services to the end users. This work presents the existing and potential services to be implemented by three main stakeholders; Airlines, Airport and ATM, during flight operations at airports.

Two highly data demanding scenarios; IFE services and situational awareness of airline operations have been discussed and analysed in detail. Selected scenarios have been further elaborated to categories the different types of data and obtain a set of required network parameters.

It has been identified that IFE services involve bulk transmission of media contents, so, multi-Gbps technology, mmWave is recommended for future communication of this service at airports. While Airline operations do not involve high data rates and these need secure data transmission, AeroMACS is suitable candidate for such operations. As a part of discussion, we have also outlined the performance improvement techniques to increase the channel utilization by applying contention mechanisms, virtualization and load balancing methods.

\section{ACKNOWLEDGMENT}

This project is carried out with the collaboration of Cranfield University, UK and Thales, UK. The authors of this publication are thankful to Thales, UK for providing funding for this study project.

\section{REFERENCES}

M. Paolini and S. Fili, "Enabling the next generation in air traffic management with AeroMACS," 2014

[2] M. Ehammer, T. Gräupl, and E. Polo, "AeroMACS data traffic model,” ICNS 2011 - Integr. Commun. Navig. Surveill. Conf. Renov. 
Glob. Air Transp. Syst. Proc., pp. 1-10, 2011.

[3] J. N. Tavares, "Data communications between an airplane Airbus a 350 and the ground infrastructure," University of Lisbon, 2014.

[4] D. Byrne, "AeroMACS secure broadband connectivity for aviation D-Taxi via AeroMACS," in Integrated Communications, Navigation and Surveillance Conference (ICNS), 2017.

[5] D. Gray, "AeroMACS - Delivering Next Generation Communications to the Airport Surface," 2015.

[6] A. Gheorghe, "EUROCONTROL Specifications on Data Link Services," 2009.

[7] J. Saucedo, "Introduction to ACARS Messaging Services - As implemented via Iridium satellite link," 2006.

[8] M. Paolini and S. Fili, "AeroMACS : A common platform for air traffic management applications," 2014.

[9] ARINC, "Media Independent Aircraft Messaging (MIAM) - ARINC Specification 841-3," 2016.

[10] E. F. Bags, F. Operations, Q. Assurance, and F. Entertainment, "Frequently Asked Questions GateLink - Airlines," pp. 1-5.

[11] ARINC, "Datalink Ground Systems Standard And Interface Specification - ARINC Specification 620-9,” 2017.

[12] D. Byrne, "AeroMACS At Glance ... Moving Towards the Airport 3.0," 2018.

[13] P. Di Michele, "Seamless Aeronautical Networking Through Integration of Data Links, Radios and Antennas," 2013.

[14] M. A. Albacete, "AeroMACS System Requirements Document," 2010.

[15] ARINC, "On-Ground Aircraft Wireless Communication - ARINC Specification 822A," 2016.

[16] James M. Budinger and Edward Hall, "Aeronautical Mobile Airport Communications System (AeroMACS)," NASA Glenn Research Center, ITT Corporation, USA, 2013.

[17] G. Vivaldi, "AeroMACS Data Link Technology for Total Airport Services," 2018.

[18] J. Guan, Y. Lu, K. Xie, F. Sheng, and F. Yang, "A virtual collision solution scheme based on optimal window for WLAN," in Proceedings - International Conference on Networks Security, Wireless Communications and Trusted Computing, NSWCTC 2009, 2009, vol. 1, pp. 421-424.

[19] J. Tan, S. Xiao, S. Han, Y. C. Liang, and V. C. M. Leung, "QoSAware user association and resource allocation in LAA-LTE/WiFi coexistence systems," IEEE Trans. Wirel. Commun., vol. 18, no. 4, pp. 2415-2430, 2019.

[20] X. Yanyi and W. Shuzong, "Virtual contention window based scheme for service differentiation over IEEE 802.11 wireless LAN," in 2006 International Conference on Wireless Communications, Networking and Mobile Computing, WiCOM 2006, 2007, vol. 2, pp. $1-5$.

[21] A. Ting, A. M. Ghaleb, Kae Hsiang Kwong, Kim-Chuan Lim, D. Chieng, and Heng-Siong Lim, "Throughput Analysis of IEEE802.11n using OPNET,” 2013, no. January 2014, pp. 014-014.
R. Krishan and V. Laxmi, "IEEE 802.11 WLAN Load Balancing for Network Performance Enhancement," Procedia Comput. Sci., vol. 57, no. February 2017, pp. 493-499, 2015.

[23] K. Ginnan, K. Kawano, K. Kinoshita, and T. Watanabe, "Access point virtualization for multiple services in heterogeneous WLANs," in 2017 14th IEEE Annual Consumer Communications and Networking Conference, CCNC 2017, 2017, pp. 704-707.

\section{AUTHORS AND AFFILIATIONS}

Dr. Shahid Ayub has been working as a Research Fellow at center of Autonomous and Cyberphysical systems, Cranfield University, UK. He has received his M.SC degree in Electrical Engineering \& Information Technology from Leibniz University Hannover Germany in 2006 and $\mathrm{PhD}$ in Communication Systems from Lanacster University, UK in 2014. His areas of interests are datalink communications systems, autonomous vehicles and human machine interface, Wireless networking of drones, Wireless industrial automation systems, Security and privacy, and Internet of things.

Before that he has worked as a senior R\&D engineer at HW Communication Systems, Lancaster, UK. Dr. Ayub has over 12 years of multi-disciplinary research experience and worked on a number of projects supported by industrial partners and research funding organizations (Innovate UK, CDE, HMGCC and HORIZON 2020) in the area of broadband communication system design, wireless sensor systems, statistical analysis, artificial intelligence algorithm design for localization and positioning, RF propagation and antenna design for high data rate Electromagnetic surface wave communication systems, Visible light communication system(VLC), and Context- \& User- Aware Networks.

Dr. Ivan Petrunin received his MSc degree in Design and Manufacturing of Electronic Equipment from National Technical University of Ukraine in 1998, $\mathrm{PhD}$ degree in Signal Processing for Condition Monitoring from Cranfield University, UK, in 2013.

At the present time he holds position of Lecturer in Digital Signal Processing in the Centre for Autonomous and Cyber-Physical Systems at Cranfield University. His research focus is in areas of applied signal processing for autonomous systems, communications and remote sensing as well as for nondestructive testing, evaluation of materials and structures, condition monitoring of rotating machinery.

Prof. Antonios Tsourdos received the M.Eng. degree in electronic, control and systems engineering from the University of Sheffield, Sheffield, U.K., in 1995, the M.Sc. degree in systems engineering from Cardiff University, Cardiff, U.K., in 1996, and the Ph.D. degree in nonlinear robust missile autopilot design and analysis from Cranfield University, Cranfield, U.K. in 1999.He is currently a Professor of control systems with Cranfield University, where he was the Appointed Head of the Autonomous Systems Group in 2007. He has published over 100 peer-reviewed journal and conference papers.

Prof. Tsourdos was a member of the Team Stellar, the winning team for the U.K. MoD Grand Challenge in 2008 and the IET Innovation Award (Category Team, 2009). He is an editorial board member on several international publications, including IMechE and IEEE. He is a member of the IFAC Technical Committee on Intelligent Autonomous Vehicles, the IET Executive Team on Robotics and Automation, and the ATI Autonomous Systems National Technical Committee. He was also involved in the SEAS DTC on Autonomous Systems Verifications. He has also been engaged in research on guidance and control for single and multiple vehicles as well as verifiable autonomy of autonomous systems and lately dealing with the newly important subjects of integrated system health management and cyber-physical systems.

Zhengjia Xu received his B.S. degree in Civil Aviation Electrical and Electronic Engineering, and his M.S. degree in Vehicle Operation Engineering from Nanjing University of Aeronautics and Astronautics, Nanjing, China, in 2014 and 2017, separately. He is currently working towards his Ph.D. degree at Cranfield University. His research interests are currently related to advanced communication system with cross-layer design for UAV applications. He is interested in cognitive radio, deep neural network and learning, handoff technologies, and software defined radio/ network. 
2020-04-30

\title{
Analysis of wireless connectivity applications at airport surface
}

\author{
Ayub, Shahid
}

IEEE

Ayub S, Petrunin I, Tsourdos A, Xu Z. (2020) Analysis of wireless connectivity applications at airport surface. In: 2019 IEEE/AIAA 38th Digital Avionics Systems Conference (DASC), 8-12 September 2019, San Diego, USA

https://doi.org/10.1109/DASC43569.2019.9081628

Downloaded from Cranfield Library Services E-Repository 